aureus, the most potent pathogen of the genus staphylococcus. The albus strains of staphylococcus are considered to be of feeble pathogenicity and of little importance other than in mild suppurative conditions of the skin.

The existence of a species producing a porcelain white colour, yet distinct from the recognized Staphylococcus albus, was first described by Welch in 1891 and named Staph epidermidis albus. The same organism was isolated by Gordon in 1903 . It is described in more recent literature under the name of Staph. epidermidis by Bergey, by Kolmer and Boerner and by Topley and Wilson.

Since this genus is agreed to be of feeble pathogenicity and a habitant of normal skin, it is considered of interest to report here a fatal case of sepsis, with multiple brain abscesses, which was encountered recently in which the offending organisms was proved to be the usually innocuous Staphylococcus epidermidis.

In our patient the portal of entry to the blood stream may have been an abraded or infected clavus on the fourth toe of the left foot. The apparent duration of the fulminating septicæmia was not over 5 or 6 days. Clinically, in the terminal phase, the case resembled meningococcic meningitis with meningococcæmia. Differential diagnosis was established by bacteriological study of blood and spinal fluid cultures taken before death and by smear and culture of the lesions in the heart, brain and intestine at necropsy, all of which yielded a pure growth of Staphylococcus epidermidis.

\section{Progress in Treatment of Subacute Bacterial Endocarditis}

(From the United States Naval Medical Bulletin, Vol. 46, May 1946, p. 763)

ThREe HUNDRED AND FORTY-SEVEN proved cases of subacute bacterial endocarditis treated at the Peter Bent Brigham Hospital from 1913 to 1945 were studied. There were no known recoveries among 237 cases seen between 1913 and 1937, during which time a great variety of therapeutic procedures was employed.

Of the 90 cases observed from 1937 to 1943, 55 received adequate treatment with a sulphonamide. Sixteen of the latter patients were given simultaneous fever therapy. Of these, one treated by infra-red radiation and three treated by typhoid vaccine recovered and have remained well for from 2 to 4 years. None of the other sulphonamide-treated patients recovered.

Of 20 patients studied since January 1944, 17 were given large doses of penicillin. In 11 cases the infection has been cured or arrested and the patients are now alive. The follow-up periods vary between 6 and
18 months. In two others the infection was bacteriologically arrested but death occurred some weeks later because of complications.

\section{Soya Bean}

(Abstracted from the Current Science, Vol. 15, June 1946, p. 158)

THE results of the co-ordinated investigations carried out in the four laboratories at Bombay, Coonoor, Dacca and Lahore, under the auspices of the I. R. F. A., have recently been published as a Special Report (I. R. F. A. No. 13).

The biological value and digestibility coefficient of the soya bean protein by growth and metabolic studies on albino rats and in human beings were found to be of the same order as those of the other pulses. In spite of its high available protein content ( $1 \frac{1}{2}$ to 2 times that of pulses) soya bean did not prove any better than the common Indian pulses as a supplement to the poor rice diet. In most experiments Bengal gram seems to have given better results than even soya bean. Incidentally it has been found that the so-called 'poor Madrasi' diet suffers more from a lack of minerals and vitamins than from that of proteins.

One of the methods of processing soya bean for human consumption is to prepare a milk-like fluid from it. Soya bean is softened by steeping for varying periods in warm water and is then ground with further addition of water. When coarse particles are removed by sieving an emulsified fluid is left behind. The emulsion thus obtained looks like milk and in composition varies according to $(a)$ the method of preparation and (b) the quantity of water added. For ages 'soya milk' thus prepared has been used in China; the main reason for its extensive use in certain regions in China is the almost complete absence of cow's milk from the prevalent human dietary. The soya emulsion prepared as above is inferior even after fortification with salts and vitamins in nutritive value as compared with fresh whole milk. There could be no doubt that an emulsion from the germinated bean would give a preparation with a greater nutritive value as compared with that obtained from untreated beans. There is little proof, however, to show that it approaches cow's milk, although it may appear to be so by virtue of its chemical composition; this is a crude way of comparing two biologicals. The I. R. F. A. Report makes it clear that all the available evidence points to the conclusion 'that soya bean preparations, if fed to infants, need to be supplemented by minerals and vitamins and that even after such supplementation they are less satisfactory than breast milk or cow's milk'.

\title{
Reviews
}

PREVENTIVE MEDICINE-By M. F. Boyd, M.D., M.S., C.P.H. Seventh Edition. 1945. W. B. Saunders Company, Philadelphia and London. Pp. X plus 591. Illustrated. Price, 27s. 6d.

THE seventh edition of this book incorporates the current advances on preventive medicine, involving extensive changes in the volume. Those diseases and deficiencies whose causes are sufficiently well known and which are therefore more or less preventable have been dealt with in the book. Naturally the diseases caused by micro-organisms occupy a large part of it. and along with them are considered water, milk and other foodstuffs, and the parts they play in transmitting infection. The disposal of excreta is fully treated in two chapters with several illustrations. The section on nutrition has been practically rewritten in the light of recent concepts. Other subjects dealt with are occupational diseases, the puerperal state, heredity and disease, and hygiene of infancy and childhood. The last two sections are on vital statistics and public health. The book presents salient features of preventive medicine with special emphasis on methods of control and with an eye on the sociological nature of the problems. It is a sound and well-balanced book.

\section{R. N. C.}

\section{DISORDERS OF THE BLOOD : DIAGNOSIS, PATHOLOGY, TREATMENT AND TECHNIQUE.- By Sir Lionel E. H. Whitby, C.V.O., M.C., M.A., M.D. (Cantab.), F.R.C.P. (Lond.), D.P.H., and C. J. C. Britton, M.D. (New Zealand), D.P.H. FIfth Edition. 1946. J. and A. Churchill Limited, London. Pp. xii plus 665, with 15 plates (10 coloured) and 71 text-figures. Price, 30 s.}

THis standard book has been thoroughly revised and brought up to date in every respect. Many changes have been made in the chapters on the origin and 
development of the blood cells, the hæmolytic anæmias, the anæmias of infancy and childhood, hæmagglutination and blood transfusion. The text has been increased by sixty-two pages and some coloured -illustrations have been included. The book provides a balanced and accurate account of modern knowledge on diseases of the blood, and is too well known to require recommendation.

\section{R. N. C.}

\section{AN ATLAS OF THE COMMONER SKIN DISEASES.-} By Henry C. G. Semon, M.D. Third Edition. 1946. Pp. viii plus 343 , with 139 plates in colour. John Wright and Sons Ltd., Bristol. Price, 25s.

ONE has nothing but praise for this book of 139 lifelike portraits, in spite of its somewhat limited utility in India.

Descriptions of the diseases depicted in the plates create an atmosphere of a clinic where 139 cases are being shown and discussed. A few less common diseases, without which the book would have been incomplete, are also included. The treatment is complete and up to date, though brief.

Of special interest are the following items: (1) A case of Exfoliative Dermatitis developing Mycosis Fungoides. (2) Treatment of eczema with urinary proteose. (3) Chronic Superficial Glossitis of latent syphilis with a weak or negative WR. (4) Unsuitability of sulphonamides for epidermal cells which are liable to be sensitized. (5) Abatement in chronic Sycosis Barbæ after replacement of ordinary razor by electric razor-scissors action. (6) Successful treatment of Pemphigus Vegetans with malaria.

The paper and printing are excellent. The binding could have been better. The price for a book of this type is reasonable.

$$
\text { S. D. S. G. }
$$

A POCKET MEDICAL DICTIONARY.-Compiled by L. Oakes. Seventh Edition. 1946. Pp. Xx plus 430. E. and S. Livingstone LImited, Edinburgh. Price, 4s. net

Sister OAKes has brought out a seventh edition of the dinky little dictionary she compiled thirteen years ago. It is a concise and compact pocket volume complete in all details, compatible with its size.

Paper, printing and binding are excellent. The price is moderate.

$$
\text { S. D. S. G. }
$$

A SHORT PRACTICE OF SURGERY:-By Hamilton Bailey and R. J. MoNeill Love. Seventh Edition. 1946. H. K. Lewis and Company, Limited, London. Pp. viii plus 1097, with 1,063 illustrations of which 203 are coloured. Price, 40s. net

THE appearance of this new edition is most welcome for three reasons. Firstly, because it is a favourite and reliable text and everyone likes to see an old friend again. Secondly, because its appearance at this time gives renewed evidence of its vigour. Thirdly, because it is the only text containing an up-to-date assimilation to practice of the many proved advances which have taken place during this last war. The patient and persistent labour the authors have put into this work under the trying conditions prevalent in England during and since the war cannot be realized by the average reader, who, treated to a masterpiece such as this edition, is all too apt to demand more from where it came without thought as to what a labour of love the making of such a book is.

The contents, as always, are concisely accurate. The pictures speak more than any written paragraph. The historical references in the footnotes give the whole an enlivening culture sadly absent these days from the average surgical text.

This text should be in the hands of every medical student and practitioner. It cannot be absent from the desk of the practising surgeon and teacher and would be a grave omission from the desk of the fellowship candidate.

$$
\text { A. T. A. }
$$

\section{DEMONSTRATIONS OF PHYSICAL SIGNS IN CLINICAL SURGERY.-By Hamilton Bailey, F.R.C.S. Tenth Edition, Revised. 1946. John Wright and Sons Ltd., Bristol. Pp. xii plus 375, with 573 illustrations, a number of which are in colour. Price, 30s.}

THE number of coloured illustrations in this edition has increased to the enhanced usefulness of the book. Its slimness is welcome, for the beauty of this book lies in the fact that it gives the surgeon the meat of the classics on diagnosis in easily assimilable form. One is tempted to describe the accessibility of the contents in terms appropriate to these days of quick lunch counters and air travel by saying 'It's all on the plate' and it is full of 'Happy landings'.

This book and all Mr. Bailey's : work are too well known to require recommendation. The names of Bailey and his publishers are synonymous with conciseness and accuracy, beauty of reproduction, in short a genuine work of art.

To the student, under-graduate and post-graduate seeking to equip themselves with a surgical library one can safely recommend a set of Hamilton Bailey's works.

A. T. A.

DISEASES OF THE SKIN. FOR PRACTITIONERS AND Students.-By G. C. Andrews, A.B., M.D. Third Edition. 1946. W. B. Saunders Company, Philadelphia and London. Pp. vi plus 937, with 971 illustrations. Price, 50s.

THis useful book might as well be called an exhaustive atlas of skin disease in view of its 937 pictures which although only in black and white are excellent. Unusual items include 'Dermatitis from Chromium Wrist Watch' (on page 105).

The presentation of the subject though concise includes all details of anatomy, diagnosis, up-to-date treatment and prognosis. An advance in anatomy is the importance of the prickle-cell layer which in healing wounds gives rise to the basal layer (page 1). Unusual items include Occupational Leukoderma (on page 840) and Electrogalvanic Lesions of the Oral Cavity produced by metals and cements used in dentistry (on page 805).

Sections on physical therapy employed Dermatology excel in brevity, clarity and utility anything the reviewer has seen in books of this size. One of them has been specially written by a radiologist.

Venereal diseases include Reiter's disease (page 281) and Behcet's Triple-symptom Complex (page 405). The chapter on syphilis has 88 pages and together with observations made elsewhere in the book (e.g. 'Antisyphilitic treatment of leukoplakia of the tongue is undesirable' on page 807) gives a complete plan of diagnosis and treatment of the disease as a whole. In this otherwise valuable section two flaws have crept in, due probably to re-writing of the book: some pictures have been separated from the text (e.g. description of annular syphilis on page 426 but its picture on page 470) and others displaced altogether (e.g. figure 429 on page 471 is not one of a mucous patch described on page 424 ; figure 523 on page 490 , referred to on page 429 , is not one of juxta-articular nodules which are shown in figure 526 , on page 492 ).

Re-writing is probably also responsible for the lack of orthodoxy in references: (1) Many of them are not found in the text. The list at the end of chapter 1 , on page 13, has 20 references out of which only 2 are found in the text. (2) They are neither numbered nor alphabetically arranged. (3) As indicated by their titles, most of them constitute a bibliography really.

Tropical diseases have been included; Bejel, however, is missing.

The book has been offered, modestly, to practitioners and students. As a matter of fact it is a book for the 